\title{
Comparison of non-cooperative and Nash bargaining solution in micro grids load distribution
}

\author{
Isaac KARGAR $^{1}$, Seifollah BAHRAMI ${ }^{2}$, Morteza AMINI ${ }^{3}$ \\ ${ }^{1}$ Faculty of Electrical \& Computer Engineering-University of Tehran, Tehran, Iran \\ Email: kargarisaac@ut.ac.ir \\ ${ }^{2}$ Faculty of Electrical \& Computer Engineering-University of Tehran, Tehran, Iran \\ Email: sbahrami91@ut.ac.ir \\ ${ }^{3}$ Faculty of Electrical \& Computer Engineering-Tarbiat Modares University, Tehran, Iran \\ Email: morteza.amini@modares.ac.ir
}

\begin{abstract}
Micro grids that use the distributed energy resources are known as an essential part of smart grid technology. In this article, we discuss and compare the strategies of the micro grids (solar panels, wind turbines, etc.) in a network that their amounts of powers have been investigated in two modes: non-cooperative mode and Nash bargaining solution. Simulation results show that in the Nash bargaining solution, it can be achieved more profit with less production.
\end{abstract}

Keywords: non-cooperative games, Nash bargaining solution, micro grid, profit

\section{Introduction}

Nowadays, smart grids, due to their ability to increase the efficiency and reliability of power and energy through the world, are increasing worldwide (1). The micro grids made of distributed energy resources such as solar cells, wind turbines and other renewable energy sources have to meet the needs of various customers in system and their needs and powers to the main network in connected mode or apart from it (2).

In (3), there has been used a comparative game solution to gain performance strategy of the micro grids and has been suggested a method that examines each micro grid within the network has the coalition with which micro grids to pay the lower cost. In (4), there has been used the wireless sensor networks for a reliable connection between the energy sources in the micro grid. In (5), there has been used a number of strategies to control the spread of the micro grids and allow the micro grids to have the proper operation in separate form from the main network.

In this article, there has been used the reference costs (3) in the profit function and the optimized function has been considered in form of benefit level of every micro grid. Following, we discuss the profit model for each micro grid and then deliver the game model. So, we investigate whether there are the conditions to use Nash bargaining solution or not.

After that, we achieve the relations for the number of two micro grids in both noncomparative mode and Nash bargaining solution and then we investigate the game solution 
for more micro grids with the results of simulation. Finally, there are provided conclusions and analysis.

\section{The profit model of a micro grid}

Using (3) that is a model of cost for the comparative game delivered in every micro grid, there has been achieved a model for a game and it has been used in analysis. In (3) of every micro grid, a production rate (Gi), a demand rate (Di) and a variable (Qi) have been defined as follows:

$$
\mathrm{Q}_{\mathrm{i}}=\mathrm{G}_{\mathrm{i}}-\mathrm{D}_{\mathrm{i}}
$$

If this expression is positive, it means that the micro grid has the additional production rate and can sell this additional production and if this expression is negative it means that the micro grid has lack of production to meet its demand of the area and it needs to purchase its power shortage from the network. If the micro grids have no cooperation, they should have power exchange with the main smart network by macro station because the voltage level between the macro station and the micro grid is at medium level (U0) and the distance to the macro station, energy loss and the cost are high. The micro grids with additional power (seller) can sell power to the micro grids with lack of power (seller). The power dissipation model is proposed as follows:

$$
P_{i 0}^{10 s \varepsilon}=R_{i 0} I_{0}^{2}+\beta P_{i}\left(Q_{i}\right)=\frac{P_{i}\left(Q_{i}\right)^{2} R_{i 0}}{U_{0}^{2}}+\beta P_{i}\left(Q_{i}\right)
$$

Where Rio is the resistance of transmission line between the micro grid Nth and macro station; $\beta$ is power dissipation in transformer in macro station $I_{0}=\frac{P_{1}\left(Q_{l}\right)}{U_{0}}$ is the transmission line when transmitting power and $\mathrm{U} 0$ is the voltage of transmission line.

Also, $\mathrm{D}$ and $\mathrm{G}$ and $\mathrm{Q}$ are the random variables and only the utility function defined below has been optimized for every micro grid: $\omega_{i}$

$$
u(\{i\})=-\omega_{\mathrm{i}} \mathrm{P}_{\mathrm{i0}}^{\mathrm{logs}}
$$

That $\omega \mathrm{i}$ is the paid price for the micro grid Nth for one unit of additional power and the 
negative mark is a sign to convert the problem into a maximization problem.

In $0, P_{i}\left(Q_{i}\right)$ has defined as below:

$$
P_{i}\left(Q_{1}\right)=\left\{\begin{array}{l}
Q_{i}, \text { if } Q_{i}>0 \\
L_{i}^{*}, \text { if } Q_{i}<0 \\
0, \quad \text { o.w. }
\end{array}\right.
$$

That $\mathrm{Li}$ is the power amount that should be produced in order to make sure that the amount of power required by the micro grid after crossing the line and taking the death toll to reach micro grid. Li can be obtained from the following equation:

$$
L_{i}=\frac{L_{i}^{2} R_{i 0}}{U_{0}^{2}}+\beta L_{i}-Q_{i}
$$

According to resistance level $\boldsymbol{R}_{i 0}$, required power $Q_{i}$ and deal voltage $U_{0} ; 0$ can have any answer, one answer or two answer. If the equation has two positive answers, smaller number is considered as the answer and this means that less waste can be considered in line. It the equation has no answer; $\mathrm{Li}$ is considered as follows:

$$
L_{i}^{*}=\frac{(1-\beta) U_{0}^{2}}{2 R_{i 0}}
$$

A comparative game is defined as a pair $(N, v)$ that $\mathrm{N}$ is a collection of players and $v: 2^{N} \rightarrow R$ is a function that considers a real number for each coalition $A \subseteq N$ showing total profit gained by the coalition A. Every coalition A has been divided into two parts:

The group of seller shown by $A_{s} \sqsubseteq A$ and the group of buyers shown by $A_{b} \sqsubseteq A$ as $A_{g} \cup A_{b}=A$. The members of $A_{g}$ have additional power and want sell this amount. The members of $\mathrm{Ab}$ need more power and want to buy the shortage of power.

\section{Game Model}

In this article, the demand (D) is considered in form of randomized and $P_{i}\left(Q_{i}\right)$ is supposed in 
form of $G_{i}-D_{i}$ in order to differentiate from Gi. The strategy of each micro grid is considered by $G_{i}$ and the profit model of each micro grid is considered as follows:

$$
\begin{aligned}
& \pi_{i}=\lambda G_{i}-\omega_{i} P_{i 0}^{\text {loss }} \\
& \lambda=b-\sum_{i=1}^{N} G_{i} \\
& \sum_{i=1}^{N} G_{i} \leq b
\end{aligned}
$$

where $b$ is the maximum production in all micro grids. In this article, using the profit function, the non-comparative modes and Nash bargaining solution have been investigated and compared for a number of different micro grids.

\subsection{Investigation of use terms from Nash bargaining solution}

To solve problems of bargaining, the area $\mathrm{S}$ should be Convex or Compact. To investigate this term intuitively and comprehensively, there has been considered two performers (gamers) in order to gain possible profit for them. By drawing benefit, one in terms of another, the area $S$ is gained in form of figure 2 :

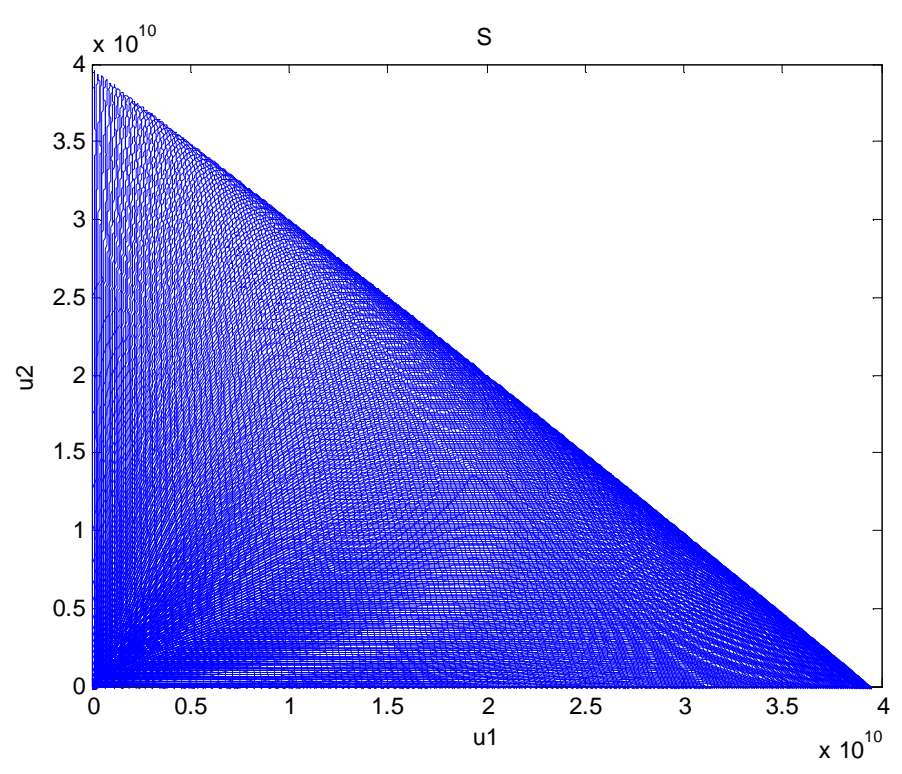

Fig. 2: S Area 
According to figure 2, it is observed that the area is convex or compact. Therefore, the conditions are prepared to use Nash bargaining solution and suggested function of Nash.

Nash has stated some rules that to know, by using them, at what point or points in the area $\mathrm{S}$ the shares are divided fairly.

- Pareto Optimality

According to this rule, the answer is on the boundary of the area S.

- Symmetry

If $d_{1}=d_{2}$ and $S=\left\{\left(U_{2}, U_{1}\right) \mid\left(U_{1}, U_{2}\right) \in S\right\}$, then $\varphi_{1}(S, d)=\varphi_{2}(S, d)$. If the conditions of gamers are fully symmetric, they should act symmetrically.

- Scale Invariance

$$
S^{\prime}=\left\{\left(\lambda_{1} U_{1}+\gamma_{1}, \lambda_{2} U_{2}+\gamma_{2}\right) \mid\left(U_{1}, U_{2}\right) \in S\right\}
$$

If for a pair of numbers:

$\left(\lambda_{1}, \lambda_{2}\right)>0,\left(\gamma_{1}, \gamma_{2}\right)$

Then:

$$
S^{\prime}=\left\{\left(\lambda_{1} U_{1}+\gamma_{1}, \lambda_{2} U_{2}+\gamma_{2}\right)\left\{\left(U_{1}, U_{2}\right) \in S\right\}\right.
$$

And: $\varphi_{1}\left(S^{\prime}, d^{\prime}\right)=\left(\lambda_{1} \varphi_{1}(S, d)+\gamma_{1}, \lambda_{2} \varphi_{2}(S, d)+\gamma_{2}\right)$

Then, the answer is scale. It means that if the area is scale, there should be gain the answer.

Independence of Eleventh Alternatives

$$
\varphi\left(S^{\prime}, d\right)=\varphi(S, d)
$$

Then:

$$
S^{\prime} \subseteq S, \varphi(S, d) \in S^{\prime}
$$

If:

considers these rules for every subset of convex box:

$$
\varphi(\mathrm{S}, \mathrm{d})=\arg _{\mathrm{UeS}, \mathrm{ud}} \max \left(\mathrm{U}_{1}-\mathrm{d}_{1}\right)\left(\mathrm{U}_{2}-\mathrm{d}_{2}\right)
$$


In other parts, by using mentioned function, the results will deliver for two modes: noncomparative mode and NBS and finally there will investigate the rules.

Non-comparative solution and Nash bargaining solution for two gamers:

Now, we solve the problem using derivation for two gamers and use the simulation with MATLAB environment for more gamers.

$\checkmark$ Non-comparative solution:

In this case, the benefit derived by each gamer should be considered to the same strategy of the gamer and considered equal to zero in order to gain Best Responses (BR) of each gamer and then the strategy and profit of each gamer can be obtained by intersection of BR.

$$
\begin{aligned}
& \frac{\partial \pi_{i}}{\partial G_{i}}=-G_{i}+b-G_{1}-G_{2}-2 \frac{\omega R_{i 0}}{U_{0}^{2}}\left(G_{i}-D_{i}\right)-\omega \beta=0 \\
& G_{1}=\frac{2 U_{0}^{2}\left(U_{0}^{2}+R \omega\right)\left(b-\beta \omega+\frac{2 D_{1} R_{i 0} \omega}{U_{0}^{2}}\right)}{4 R_{i 0}^{2} \omega^{2}+8 R_{i 0} U_{0}^{2}+3 U_{0}^{4}}-\frac{U_{0}^{4}\left(b-\beta \omega+\frac{2 D_{2} R_{i 0} \omega}{U_{0}^{2}}\right)}{4 R_{i 0}^{2} \omega^{2}+8 R_{i 0} U_{0}^{2} \omega+3 U_{0}^{4}} \\
& G_{2}=\frac{2 U_{0}^{2}\left(U_{0}^{2}+R \omega\right)\left(b-\beta \omega+\frac{2 D_{2} R_{i 0} \omega}{U_{0}^{2}}\right)}{4 R_{i 0}^{2} \omega^{2}+8 R_{i 0} U_{0}^{2}+3 U_{0}^{4}}-\frac{U_{0}^{4}\left(b-\beta \omega+\frac{2 D_{1} R_{i 0} \omega}{U_{0}^{2}}\right)}{4 R_{i 0}^{2} \omega^{2}+8 R_{i 0} U_{0}^{2} \omega+3 U_{0}^{4}}
\end{aligned}
$$

The results have been delivered in nest section.

$$
\checkmark \text { Nash bargaining solution }
$$

In this state, the problem should be solved by 0 :

$$
\begin{gathered}
\stackrel{\frac{\partial}{\partial G_{3}}}{\longrightarrow}\left(d_{2}+G_{2}\left(G_{1}+G_{2}-b\right)-\beta \omega\left(D_{2}-G_{2}\right)+\frac{R_{i 0} \omega\left(D_{2}-G_{2}\right)^{2}}{U_{0}^{2}}\right) \ldots \\
\times\left(2 G_{1}+G_{2}-b+\beta \omega-\frac{R_{i 0} \omega\left(2 D_{1}-2 G_{1}\right)}{U_{0}^{2}}\right) \ldots \\
+G_{2}\left(d_{1}+G_{1}\left(G_{1}+G_{2}-b\right)-\beta \omega\left(D_{1}-G_{1}\right)+\frac{R_{i 0} \omega\left(D_{1}-G_{1}\right)^{2}}{U_{0}^{2}}\right)=0
\end{gathered}
$$




$$
\begin{aligned}
\stackrel{\frac{\partial}{a G_{2}}}{\rightarrow}\left(d_{1}+G_{1}\left(G_{1}+G_{2}-b\right)-\beta \omega\left(D_{1}-G_{1}\right)+\frac{R_{i 0} \omega\left(D_{1}-G_{1}\right)^{2}}{U_{0}^{2}}\right) \ldots \\
\times\left(2 G_{2}+G_{1}-b+\beta \omega-\frac{R_{i 0} \omega\left(2 D_{2}-2 G_{2}\right)}{U_{0}^{2}}\right) \ldots \\
+G_{1}\left(d_{2}+G_{2}\left(G_{1}+G_{2}-b\right)-\beta \omega\left(D_{2}-G_{2}\right)+\frac{R_{i 0} \omega\left(D_{2}-G_{2}\right)^{2}}{U_{0}^{2}}\right)=0
\end{aligned}
$$

Now, by solving two mentioned equations, it can be found the strategy of each micro grid and its profit. The results have been shown in next section.

\section{The results of stimulation}

\subsection{Mode 1}

Suppose the maximum D is fixed for total area and the number of micro grids is increasing, demand is divided between them. To sole the bargaining solution, there has been used the genetic algorithm and PSO in each stage, due to large numbers of gamers, to maximize the issue. In figure 1-9, there have been shown the strategies and the profit of each gamer for different gamers. The amounts of available variables are as follows:

$$
\begin{aligned}
& R=0.2 \frac{\Omega}{k m}, \beta=0.02, U_{0}=50 \mathrm{kV}, \\
& \omega_{i}=1 \text { for } i=1, \ldots, N, b=400 \mathrm{~kW}
\end{aligned}
$$

The demand is considered as a normal distribution. If there are two gamers, this normal distribution is $N\left(100 \times 10^{3}, 33 \times 10^{3}\right)$. If there are three gamers, the normal distribution is $N\left(66 \times 10^{3}, 22 \times 10^{3}\right)$ and if there are four gamers, the normal distribution is $N\left(50 \times 10^{3}, 17 \times 10^{3}\right)$, as well as ongoing until if there are ten gamers, the normal distribution is $N\left(20 \times 10^{3}, 6.6 \times 10^{3}\right)$. Indeed, the demand for each micro grid decreases by increasing the micro grids uniformly but the total demands in the center of demand are 200 $\mathrm{K}$. The maximum amount of total micro grids is considered $400 \mathrm{KW}$. To stimulate them, we consider the increase of micro grid levels with the distance from the macro station with a normal distribution $\mathrm{N}(200.80)$ that this distance multiplies in resistance and the total 
Bulletin de la Société Royale des Sciences de Liège, Vol. 85, 2016, p. 153 - 165

resistance of the line between the micro grid and macro station will result. Points of disagreement on this issue ( 0 and 0$)$ are considered. 
Bulletin de la Société Royale des Sciences de Liège, Vol. 85, 2016, p. 153 - 165

Table 1: The strategy and profits of gamers in two modes of Nash bargaining solution and non-comparative

\begin{tabular}{|c|c|c|c|}
\hline & & $\begin{array}{c}\text { Non } \\
\text { Cooperative }\end{array}$ & NBS \\
\hline \multirow{2}{*}{$\begin{array}{c}\text { two } \\
\text { gamers }\end{array}$} & $G_{1-2}\left(10^{3}\right)$ & 133.34 & 100 \\
\hline & $U_{1-2}\left(10^{8}\right)$ & 177.78 & 200 \\
\hline \multirow{2}{*}{$\begin{array}{c}\text { three } \\
\text { gamers }\end{array}$} & $G_{1-3}\left(10^{3}\right)$ & 100 & 66.67 \\
\hline & $U_{1-3}\left(10^{8}\right)$ & 100 & 133.34 \\
\hline \multirow{2}{*}{$\begin{array}{c}\text { four } \\
\text { gamers }\end{array}$} & $G_{1-4}\left(10^{3}\right)$ & 80 & 50 \\
\hline & $U_{1-4}\left(10^{8}\right)$ & 64 & 100 \\
\hline \multirow{2}{*}{$\begin{array}{c}\text { five } \\
\text { gamers }\end{array}$} & $G_{1-5}\left(10^{3}\right)$ & 66.67 & 40 \\
\hline & $U_{1-5}\left(10^{8}\right)$ & 44.45 & 80 \\
\hline \multirow{2}{*}{$\begin{array}{c}\text { six } \\
\text { gamers }\end{array}$} & $G_{1-6}\left(10^{3}\right)$ & 57.1 & 33.34 \\
\hline & $U_{1-6}\left(10^{8}\right)$ & 32.65 & 66.67 \\
\hline \multirow{2}{*}{$\begin{array}{l}\text { seven } \\
\text { gamers }\end{array}$} & $G_{1-7}\left(10^{3}\right)$ & 50 & 28.5 \\
\hline & $U_{1-7}\left(10^{8}\right)$ & 25 & 57.1 \\
\hline \multirow{2}{*}{$\begin{array}{l}\text { eight } \\
\text { gamers }\end{array}$} & $G_{1-8}\left(10^{3}\right)$ & 44.4 & 25 \\
\hline & $U_{1-8}\left(10^{8}\right)$ & 19.75 & 50 \\
\hline \multirow{2}{*}{$\begin{array}{c}\text { nine } \\
\text { gamers }\end{array}$} & $G_{1-9}\left(10^{3}\right)$ & 40 & 22.2 \\
\hline & $U_{1-9}\left(10^{8}\right)$ & 16 & 44.4 \\
\hline \multirow{2}{*}{$\begin{array}{c}\text { ten } \\
\text { gamers }\end{array}$} & $G_{1-10}\left(10^{3}\right)$ & 36.3 & 20 \\
\hline & $U_{1-10}\left(10^{8}\right)$ & 13.2 & 40 \\
\hline
\end{tabular}




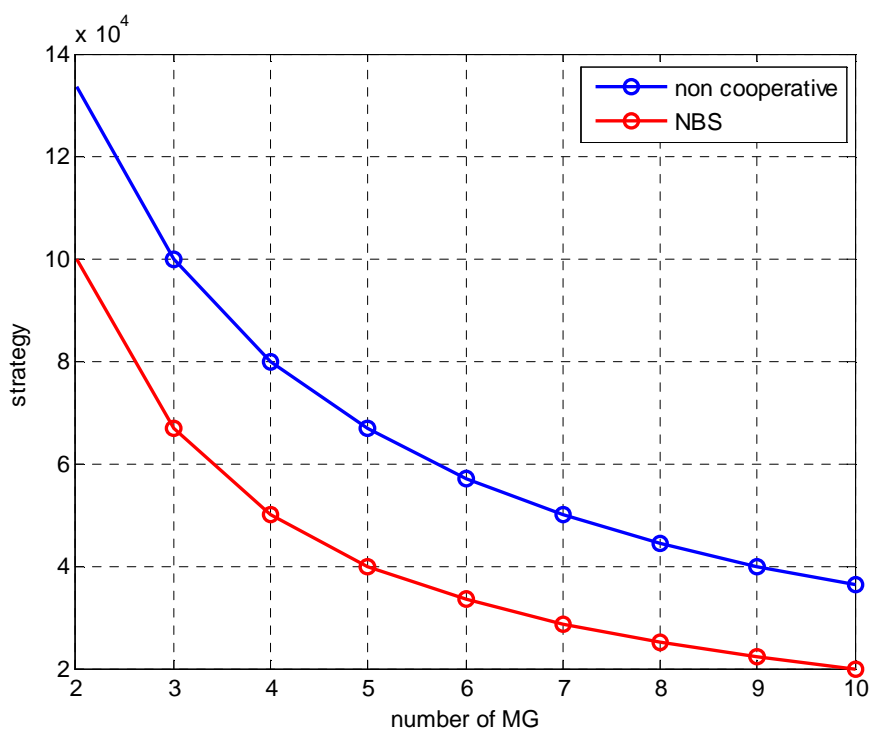

Figure 3: the strategy of every micro grid for different numbers of micro grids

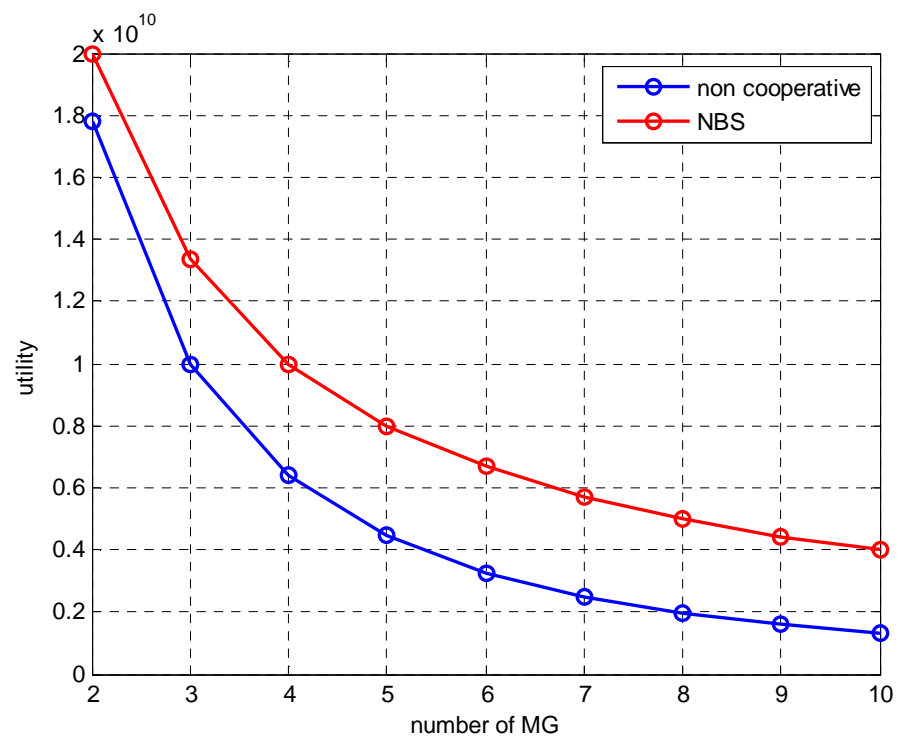

Figure 4: the profit of every micro grid for different numbers of micro grids

With regard to Table 1, it has been observed that for number of gamers, the profit and the strategy is equal and the rule 2 of Nash is met. Figures 3 and 4 show the strategy and profit of gamers for various gamers. It is obvious that in Nash bargaining solution, for numbers of gamers, the micro grids can gain more profit with low production. 


\subsection{Mode 2}

Now, there has been performed the stimulation for 5 micro grids during 10 days differently. Every day, the demand level delivered to the micro grid changes randomly due to a normal distribution and the mean of production level of all five micro grids during 10 days has been achieved according to table 2 .

Table 2: the mean of the strategy and profit of five micro grids during 10 days in two modes non-comparative and Nash bargaining solution

\begin{tabular}{ccccc}
\hline \multirow{2}{*}{ Day } & \multicolumn{2}{c}{ NBS } & \multicolumn{2}{c}{$\begin{array}{c}\text { Non } \\
\text { Cooperative }\end{array}$} \\
\cline { 2 - 5 } & $\mathrm{U}\left(10^{8}\right)$ & $\mathrm{G}\left(10^{3}\right)$ & $\mathrm{U}\left(10^{8}\right)$ & $\mathbf{G ( 1 0})$ \\
\hline 1 & 79.97 & 40.02 & 44.65 & $\mathbf{6 6 . 5 5}$ \\
\hline 2 & 79.97 & 39.98 & 44.73 & $\mathbf{6 6 . 4 8}$ \\
\hline 3 & 79.97 & 39.97 & 44.74 & $\mathbf{6 6 . 4 7}$ \\
\hline 4 & 79.95 & 39.99 & 44.70 & $\mathbf{6 6 . 5 1}$ \\
\hline 5 & 79.95 & 40.03 & 44.60 & $\mathbf{6 6 . 5 8}$ \\
\hline 6 & 79.96 & 39.97 & 44.72 & $\mathbf{6 6 . 4 6}$ \\
\hline 7 & 79.98 & 40.00 & 44.68 & $\mathbf{6 6 . 5 2}$ \\
\hline 8 & 79.98 & 40.00 & 44.69 & $\mathbf{6 6 . 5 2}$ \\
\hline 9 & 79.95 & 39.98 & 44.70 & $\mathbf{6 6 . 4 9}$ \\
\hline 10 & 79.96 & 39.97 & 44.72 & $\mathbf{6 6 . 4 8}$ \\
\hline
\end{tabular}

With regard to table 2, it has been observed that the profit and production have differences in various days that the production and profit have differences in various days due to the demand levels in every day. In Nash bargaining solution, when the number of days increases, the total profit is high with low total production. It is obvious in table 2. With regard to tables, it could be understood that the overall production is about $200 \mathrm{KW}$ for every number of micro grid in Nash bargaining solution and it is about total demand of the area. While, overall production power in non-comparative mode is higher than the demand that it is not economically.

\section{Conclusion and analysis}

According to the results, there should be investigated whether four rules of Nash have been met or not. With regard to figure 5, the game with two gamers shows the area $S$ and it is the response point of Nash bargaining solution. It is obvious that this point that specified with red color has been placed on the boundary of the area and then first rule has been met. 


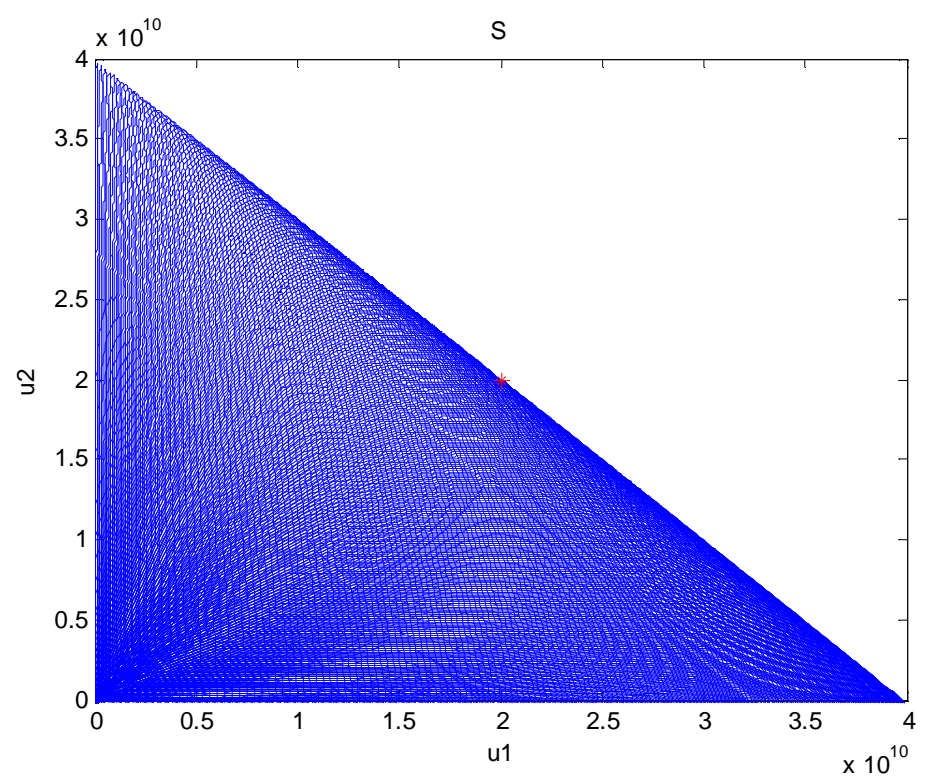

Figure 5: Area S and the response point of Nash bargaining solution

Due to the symmetry of the area $\mathrm{S}$, there should be the same the profits of two gamers. Then, this rule is met.

$U_{1}=U_{2}=200 \times 10^{8}$

To investigate third rule, the factors should be considered as follows:

$$
\begin{aligned}
& \lambda_{1}=10^{3} \\
& \lambda_{2}=2 \times 10^{3} \\
& \gamma_{1}=\gamma_{2}=0.5 \times 10^{13}
\end{aligned}
$$

Now, if obtained responses scale with these factors for the area S, we achieve below results:

$$
\begin{aligned}
& U_{1-\text { new }}=\lambda_{1} U_{1}+\gamma_{1}=2.5 \times 10^{13} \\
& U_{2-\text { new }}=\lambda_{2} U_{2}+\gamma_{2}=4.5 \times 10^{13}
\end{aligned}
$$

By scaling the area $S$ and achieving to $S^{\prime}$, solving the results are as follows: 


$$
\begin{aligned}
& U_{1}^{\prime}=2.5 \times 10^{13} \\
& U_{1}^{\prime}=4.5 \times 10^{13}
\end{aligned}
$$

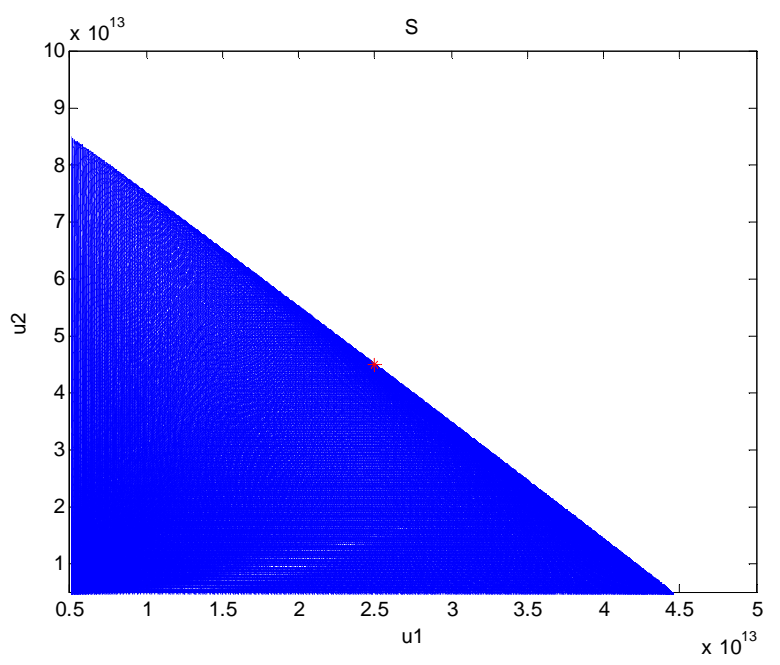

Figure 6: Area $S$ and the response point of scale invariance

According to the results, it is obvious that two modes have gained the response and this rule is met. Figure 6 shows the area $S$ and the response point of scale invariance.

Every subset $S$ is considered by $S$ containing the response of the problem for the area $S$. indeed, it concludes a subset of points that has lower profit than the response point in solving the problem for the area S. Therefore, by considering new area and this matter that these points are the subset of previous points, they have lower profit then the response point and solving problem for the area $S$ is similar to the area $\mathrm{S}$. Then, this rule is met.

So, by maximizing the suggested function of Nash, four rules suggested by Nash are met. With regard to the results, it is obvious that in Nash bargaining solution of gamers, for every gamer, it could gain more profit with low production compared to non-comparative mode. Table 2, also, shows the mean of profit and the strategy of four micro grids during different days confirmed this issue. Therefore, due to the results, Nash bargaining solution method for every gamer in the micro grid has better results.

\section{References}

[1] ISO New England Inc., "Overview of the smart grid: Policies, initiatives and needs," Feb. 2009. 
[2] N. Hatziargyriou, H. Sano, R. Iravani, and C. Marnay, "Microgrids: An overview of ongoing research development and demonstration projects," IEEE Power and Energy Magazine, vol. 27, pp. 78-94, Aug. 2007.

[3] Saad, Walid, Zhu Han, and H. Vincent Poor. "Coalitional game theory for cooperative micro-grid distribution networks." Communications Workshops (ICC), 2011 IEEE International Conference on. IEEE, 2011.

[4] G. Bag, R. Majumder, and K. Kim, "Low cost wireless sensor network in distributed generation," in Proc. International Conference on Smart Grid Communications, Gaithersburg, MD, USA, Oct. 2010.

[5] J. A. P. Lopes, C. L. Moreira, and A. G. Madureira, "Defining control strategies for microgrids islanded operation,” IEEE Transactions on Power Systems, vol. 21, no. 2, pp. 916-924, May 2006 